\title{
CONTEÚDOS IMPLÍCITOS EM TÍTULOS DE REVISTAS SEMANAIS
}

\author{
Fernando Felício Pacchi Filho ${ }^{1}$
}

\begin{abstract}
Resumo
Nas publicações jornalísticas, os títulos têm a função de apresentar ao leitor a informação mais importante e atrai-lo para a leitura. O título, nesta perspectiva, traz uma narratividade que deve conter o discurso da notícia em questão e deve ser levado em consideração no processo de leitura. No entanto, sabemos que a função de atrair o leitor não é obtida apenas pela importância da notícia ou do assunto. O jogo com os sentidos, o duplo sentido, a exploração de conteúdos implícitos são artifícios bastante usados por publicações jornalísticas, em especial as revistas semanais, nos títulos de reportagem. Não é arriscado dizer que muitos desses enunciados, além de seu conteúdo explícito, apresentam implicitação, processo que também direciona a interpretação. Neste artigo, buscamos num primeiro momento apresentar o funcionamento dos títulos jornalísticos e compreender como os conteúdos implícitos se inserem no processo de significação. Para tanto, adotamos para a análise de títulos extraídos das revistas semanais Veja e Época, a semântica histórica da enunciação, proposta por Guimarães (1995).
\end{abstract}

Palavras-chave: Jornalismo, semântica, conteúdos implícitos.

\begin{abstract}
In journalism, headings are useful to present to the readers the most important information and attract them to reading. In this way, headings have its own narrative that should present the news discourse and this must be considered in reading process. Not only the importance of the news and the subject are enough to captivate readers, but also the play with meanings, double meanings, the use of inferred subjects are common strategies in journalism, especially in headings of articles in weekly magazines. It is not a risk to say that many of these sentences have inferred subjects besides the expressed ones. This process also gives the direction for interpretation. In this article, we try at first to present how headings' meanings are semantic constructed and then to understand how inferred subjects contribute to construct headings' meanings. For this purpose, we follow the historic semantics proposed by Guimarães (1995) in the analysis of headings from weekly magazines as Veja and Época.
\end{abstract}

Keywords: Journalism, semantics, inferred subjects.

\section{Introdução}

Na leitura proposta por publicações jornalísticas, os títulos tem a missão de apresentar ao leitor a informação considerada mais importante no discurso em que se insere o veículo de comunicação tornando-se assim um gesto interpretativo dos acontecimentos construídos pela mídia. Analistas das práticas jornalísticas, como Fontcuberta (1993) e Lage (2000), consideram que os títulos devem anunciar e resumir a informação e convencer o leitor de que o viés apresentado é importante, além de atraí-lo para a leitura e "vender" para ele a importância do

\footnotetext{
${ }^{1}$ Graduado em Português/Lingüística pela USP, em Jornalismo pela PUC-SP, doutor em Lingüística pela Unicamp.
} 
texto. O título, nesta perspectiva, traz uma narratividade que deve conter o discurso da notícia em questão. No entanto, sabemos que a função de atrair o leitor não é obtida apenas pela importância da notícia ou do assunto. O jogo com os sentidos, o duplo sentido, a exploração de conteúdos implícitos, são artifícios bastante usados por publicações jornalísticas, em especial as revistas. Muitos desses enunciados, além de seu conteúdo explícito, apresentam implicitação.

Os títulos de matérias, bem como outros elementos paratextuais ${ }^{2}$ (MAINGUENEAU, 2002, p. 81) denominados no jargão jornalístico como chapéus, olhos e legendas, são definidores e constituintes da linguagem jornalística impressa, integrada por códigos verbais e visuais (LAGE, 2000), podendo ser considerados essenciais para a geração de efeitos de sentidos variados depreendidos a partir de uma análise discursiva. Neste artigo, buscamos num primeiro momento apresentar o funcionamento dos títulos jornalísticos, tendo em vista sua articulação com elementos paratextuais, especialmente, chapéus e olhos, e compreender como os conteúdos implícitos se inserem no processo de significação. Para tanto, adotamos para a análise de títulos extraídos das revistas semanais Veja e Época, a semântica histórica da enunciação, proposta por Guimarães (1995).

\section{Um caminho de leitura}

A leitura de um título jornalístico, como afirmamos acima, não pode ser desvinculada de outros elementos paratextuais, principalmente o chapéu e o olho, sob pena de não apreendermos o significado proposto. Isso porque estes elementos aliados aos títulos direcionam os sentidos da interpretação, ou seja, conferem ao enunciado uma orientação de sentidos, que deve ser levada em conta na leitura e também na análise. Consideramos, portanto, que ao conferir títulos às reportagens os locutores-jornalistas produzem um gesto interpretativo que se naturaliza nas suas condições de produção. Tomemos como referência os seguintes títulos, tratados como enunciados que se articulam com outros enunciados, no caso chapéus e olhos, extraídos das revistas Veja e Época.

(a)

Tecnologia

O Império contra-ataca

\footnotetext{
2 Maingueneau denomina paratexto "o conjunto de fragmentos verbais que acompanham o texto propriamente dito; pode se tratar de unicaades amplas (prefácios, textos figurando na capa um intertítulo, uma rubrica ("faits divers", "editorial", "anúncios" etc.), notas de rodapé, comentários na margem.
} 
A Microsoft gasta 450 milhões de dólares em campanha global para lançar o novo Windows. (Veja, 7/2/2007, p. 94)

(b)

\section{Brasil}

Governadora muito família.

Contrastanto com uma safra de bons governadores, Ana Júlia Carepa só quer saber de dar felicidade a seus parentes e amigos. (Veja, 25/4/2007, p. 58).

(c)

\section{Negócios \& Carreira}

Inovação

Deu branco!

Como a parceria entre universidade e empresa privada gerou uma tinta branca de padrão mundial. (Época, 8/1/2007, p.49)

Vida útil

Saúde

Dá para curar o mal pela raiz?

O Brasil começa a descobrir o valor de suas plantas medicinais. Eis as principais armas da fitoterapia. (Época, 16/10/2006, p. 52).

Observemos que em ambas as revistas há um funcionamento da linguagem jornalística, que busca inserir os títulos e, consequentemente, as matérias em uma classificação das notícias em assuntos ou seções determinadas pela publicação. Desse modo, podemos dizer que há um locutor que propõe esta classificação, interditando outros sentidos possíveis num esquecimento que se promove de outras classificações. Dessa forma, consideramos que os chapéus "Tecnologia" e "Brasill" - inserem os demais elementos (título e olho) numa abrangência temática, que interdita outras possibilidades de classificação e propõe um direcionamento para os sentidos, a leitura e a interpretação. Projetam-se deste modo sentidos no acontecimento enunciativo. Notemos que na revista Época há dois chapéus: o primeiro deles que corresponde à seção, que classifica a reportagem em uma determinando campo de discurso, além de outro chapéu que restringe a abrangência da seção, permitindo um direcionamento mais específico 
para o assunto. Assim, temos: "Negócios \& Carreira - Inovação" e "Vida Útil - Saúde". Propõe-se assim um encaixamento do que se trata nestes temas.

Podemos assim dizer que o chapéu das reportagens hierarquiza e direciona sentidos, não apenas informa. Há autonomia relativa destes elementos, dado que os chapéus podem corresponder a seções, como no caso de "Negócios \& Carreira"e "Vida Útil", ou apenas aos assuntos em questão, como em “Tecnologia" e "Brasill". No entanto, a compreensão do sentido geral pretendido e o efeito gerado só é possível se consideramos o título, como elemento que o locutor-jornalista utiliza para inserir, de fato, o dizer no campo da notícia, para propor um direcionamento específico para a interpretação, rememorando outros enunciados, num recorte feito a partir do interdiscurso ${ }^{3}$ (PÊCHEUX, 1997, p.162).

Observamos, porém, que nem sempre a carga informativa do título é suficiente para dizer sobre o conteúdo da matéria, mesmo porque há um uso de conteúdos implícitos que nestes casos devem ser levados em consideração. Dessa forma, o olho é o espaço para o locutorjornalista "explicar", explicitar sobre o que se fala, e também os enunciados anteriores, principalmente os títulos, dando a eles uma organização lógica no todo proposto. Esta função explicativa, portanto, demonstra que há regras para a enunciação. Se no chapéu, o locutor classifica, no título há um espaço para o jogo da linguagem com o implícito, o duplo sentido, a intertextualidade; nos olhos, predomina a explicação, da qual não se pode fugir, para ter um fechamento do sentido e cumprir a função informativa a que estas revistas se propõem. Podemos, portanto, falar em lugares de enunciação diferentes, num desdobramento do locutor em diversas funções que trabalha a linguagem em três aspectos: classificatório, lúdico e explicativo.

\section{A semântica histórica da enunciação}

Guimarães (1995) visa articular conceitos da análise do discurso, na tradição inaugurada por Michel Pêcheux, e da semântica argumentativa proposta por Ducrot (1977 e 1987), em seus aspectos enunciativos, para compor o que ele denomina a semântica histórica da enunciação. Desta forma, mantém-se uma posição materialista de não-transparência da linguagem, tomada, portanto, na sua relação com o real, que é histórica. Destacamos nesta perspectiva de que não há como considerar o funcionamento de uma forma linguística desvinculada de seu

\footnotetext{
${ }^{3}$ Pêcheux define interdiscurso como "todo complexo dominante" de formações discursivas, ou seja, ele abarca todas as múltiplas formações discursivas que condicionam o sentido.
} 
funcionamento num texto, integrando-a ainda a um acontecimento ${ }^{4}$. Desta forma, há um modo de apreensão do sentido que não é segmental.

Para Guimarães, a semântica de Ducrot tem o mérito de propor um tratamento linguístico da argumentação, tomando-a como questão enunciativa. No entanto, mantem-se nesta teoria a exclusão da história. Considera-se na semântica histórica proposta por Guimarães a significação determinada por condições sociais e pela história, definindo-se o sentido como discursivo (GUIMARÃES, 1995, p. 66) e ligado ao acontecimento enunciativo. Por isso, este autor busca mobilizar conceitos da Análise do Discurso para construir a concepção de sentido. Nesta perspectiva, a enunciação é um acontecimento de linguagem definida pelo interdiscurso, num cruzamento de enunciados de discursos diferentes que se fecham num texto. Assim, explica Guimarães sua proposta:

\footnotetext{
Uma semântica histórica da enunciação se constitui no lugar em que se trata a questão da significação ao mesmo tempo como linguística, histórica e relativa ao sujeito que enuncia. Fazer isso é aceitar que a linguagem funciona olhando para fora de si, mas este fora só se alcança porque é simbolizado, porque a linguagem não se confunde com a situação em que seus segmentos ocorrem (GUIMARÃES, 1995, p. 85).
}

Interessam nesta perspectiva semântica desdobramentos da teoria de Ducrot a partir de seu estudo sobre pressuposição e subententidos, que, conforme explica Guimarães (1995), permite ao autor considerar que o sentido do enunciado integra a representação que ele faz de sua enunciação, ou seja de seu acontecimento histórico, ligado à temporalidade. Isto quer dizer que a história é a do momento da enunciação. Ducrot incorpora assim o conceito de polifonia, que permite tratar diferenças nas representações de figuras do sujeito, mas não remetido a ele. Além disso, distingue as categorias de falante/ouvinte - não-linguísticas por serem agentes psico-fisico-fisológicos da ação de falar e ouvir; locutor/alocutário ${ }^{5}$, figura da enunciação que se representa na enunciação no par eu/tu; enunciador/destinatário, que estabelece a perspectiva da enunciação, o lugar de onde se fala.

Interessa ainda reter de Ducrot o conceito de orientação argumentativa, que consideramos produtivo na análise dos conteúdos implícitos. Neste aspecto, o autor demonstra que a argumentação é uma questão linguística, não-sujeita ao caráter lógico e que é marcada

\footnotetext{
${ }^{4}$ Guimarães (2002a, p. 11-12) explica desta forma o conceito de acontecimento: "Considero que algo é acontecimento enquanto diferença na sua própria ordem. E o que caracteriza a diferença é que o acontecimento não é um fato no tempo. Ou seja, não é um fato novo enquanto distinto de qualquer outro ocorrido no tempo. $\mathrm{O}$ que o caracteriza como diferença é que o acontecimento temporaliza. Ele não está num presente de um antes e de um depois no tempo. O acontecimento instala sua própria temporalidade: essa a sua diferença."

${ }^{5}$ No nível da figura do locutor, Ducrot distingue o que ele chama o locutro-L e o loutro-l. O locutor-L é o que se representa como fonte do dizer, enquanto o locutor-l é o locutor-enquanto-pessoa-no-mundo.
} 
nos enunciados. Assim, o próprio enunciado leva o interlocutor a conclusões, que estão na regularidade do seu sentido (GUIMARÃES 1995, p.25). O argumento não é uma prova para aceitar uma conclusão, constituindo uma relação de menor e maior força para uma determinada conclusão (GUIMARÃES, 1995, p. 50).

O pressuposto, na visão de Guimarães, deve ser analisado como efeito do já-dito que se liga à presença do interdiscurso, constituído em outro lugar, externo ao enunciado, que se apresenta como ato de um locutor único. Mas é no conceito de orientação argumentativa que se pode pensar num modo de analisar os conteúdos implícitos. A argumentação, tratada nesta perspectiva como relação de linguagem, leva a uma conclusão por sua significação, conferindo uma direção ao dizer. Neste aspecto, Guimarães considera que a "diretividade" da orientação argumentativa sustenta-se no já-dito, porque é determinada pelo interdiscurso. Assim, a orientação argumentativa também corresponde a uma forma de como se deve interpretar um enunciado, ou o próprio futuro do texto. A argumentação é um funcionamento da textualidade em que há desdobramento do sujeito em posições enunciativas. Ainda, segundo Guimarães, argumentar é silenciar outros percursos de significação no texto, num silêncio constitutivo.

É pela noção de recorte, não-segmental, que Guimarães (2002b) busca a articulação com a Análise de Discurso, assumindo também a polissemia e a incompletude constitutivas do sentido, que deve ser apreendido em sua multiplicidade e existência histórica.

Guimarães e Orlandi (1988) consideram o texto como unidade empírica que deve ser tomada como unidade de análise no processo discursivo, sendo ele atravessado por várias posições-sujeito, numa dispersão de discursos. Desta forma, a unidade de construção do discurso é o enunciado, que deve ser referido ao texto para poder ser apreendido em seu processo de construção. O enunciado, nesta perspectiva, corresponde a um recorte discursivo no texto.

\section{Análises}

Abaixo, procuramos observar o funcionamento de títulos, com o objetivo de mostrar, dentro da perpectiva aberta pela semântica história da enunciação de que a compreensão dos conteúdos implícitos está na dependência de um quadro discursivo, cujos efeitos de sentido devem ser compreendidos a partir da interpretação de suas restrições e articulações com outros enunciados disponíveis no interdiscurso.

Animais 
A política do cachorro único

Agora, cada casa em Pequim só pode ter um. E de pequeno porte. (Veja, 6/12/2006, p. 75).

Observemos o funcionamento do enunciado "A política do cachorro único", conferido como título da matéria. O locutor-jornalista categoriza no chapéu "Animais" o assunto, inserindo os enunciados seguintes "A política do cachorro único" e "Agora, cada casa em Pequim só pode ter um. E de pequeno porte" numa rede de formulações que se vinculam a um assunto principal que se refere à China, referido no olho. Há, portanto, uma direção de sentidos que deve ser respeitada no processo de leitura, que não pode fugir, a princípio, à classificação e explicação proposta na linguagem jornalística. Desta forma, busca-se silenciar outros percursos interpretativos. Mas como o sentido também se produz no equívoco do dizer, há abertura para outras interpretações que não a literal proposta. Tomados como recorte discursivo, observamos que o sentido de leitura proposto nestes enunciados não se fecha, porque há um enunciado implicitado que atua na interpretação para que haja uma compreensão além do segmento proposto. Assim, temos o enunciado "A política do filho único", que denomina a política de controle da natalidade adotada na China nos anos 80 para conter a superpopulação, evocado para a construção do novo enunciado e ao mesmo tempo mantido como conteúdo implícito e que está nas margens do enunciado "A política do cachorro único". O locutorjornalista joga, portanto, com a perspectiva de que existe uma política que limita o número de filhos, mas não a explicita no recorte. Há uma memória do dizer, uma alusão a outro enunciado de uma formação discursiva política, que condiciona o efeito de sentido, não-categorizado na proposta de leitura do recorte. Agora, esta política restritiva abrange também a posse de cães. Ocorre que a compreensão deste enunciado passa pelo entendimento da transformação ocorrida no enunciado "A política do filho único", por intervenção do locutor-jornalista, que se mantém na perspectiva de um enunciador que conhece a história recente da China e imagina um destinatário ideal capaz de compreender esta relação. Como este enunciador se coloca numa posição enunciativa de quem detem este conhecimento, a responsabilidade pela interpretação e compreensão do enunciado e seu caminho de construção fica a cargo do destinatário, que para compreender necesssita colocar em relação o que se diz e o que não se diz, mas se subentende. Desta forma, ao propor um caminho para a interpretação, o locutor-jornalista se exime da responsabilidade pelo que está implicitado.

\section{(2) Tecnologia}

O Império contra-ataca 
A Microsoft gasta 450 milhões de dólares em campanha global para lançar o novo Windows. (Veja, 7/02/2007, pag. 94)

Observemos que o chapéu "Tecnologia" vai inserir o texto dentro de um campo de discurso sobre a tecnologia, ou seja, o assunto da seção é tecnologia. Isso confere uma diretividade interpretativa, que só é possível compreender a partir de sua inserção em um campo de discurso determinado. O olho vem a explicar o título, ou seja, "O Império" é reescrito como "Microsoft", maior empresa do mundo no setor de informática, que gasta 450 milhões de dólares de para lançar novo produto. Mas vamos nos ater ao título. Ele é portador de um duplo sentido. Chapéu e olho restringem a interpretação, fechando-a sobre o assunto em questão. No entanto, é possível ver que este enunciado já foi produzido em outros contextos "O Império contra-ataca" é também o título do segundo filme da série de ficção científica Guerra nas estrelas. Este sentido está interditado pela explicação oferecida tanto no chapéu quanto no olho. No entanto, ele está lá e joga-se com ele para que haja um duplo sentido. Ele está implicitado e depende do conhecimento enciclopédico do locutário para sua interpretação. Desta forma, deve ser compreendido numa perspectiva polifônica, que contempla este sentido subentendido. Assim, o que temos é um locutor-jornalista que se representa como formulador deste enunciado e imagina um alocutário, cujo conhecimento enciclopédico permitirá compreender o efeito de sentido desejado.

Para tanto, é necessário imaginar uma unidade deste alocutário. Em termos enunciativos, podemos dizer que há então duas perspectivas de enunciação: a primeira que admite um deslizamento do enunciado do discurso da cultura para o da tecnologia e o segundo que o insere apenas no da tecnologia, oferecendo uma compreensão apenas dentro dos limites propostos para a interpretação, que se relaciona, portanto, a duas imagens de destinatário correspondentes a um enunciador que assume as duas posições. Vemos, portanto, que este implícito só pode funcionar na dependência da interpretação do destinatário, imaginado num efeito-leitor. Assim, observamos que este conteúdo implícito depende de um caminho interpretativo proposto pelo locutor, que se exime, pelo funcionamento do discurso jornalístico, de inseri-lo no campo de origem desta significação, deslocando para outro campo: o da tecnologia, que condiciona a interpretação. Busca-se o efeito de deixar o lugar da segunda interpretação para o destinatário.

Brasil 
Governadora muito família

Contrastando com uma safra de bons governadores, Ana Júlia Carepa só quer saber de dar felicidade a seus parentes e amigos. (Veja, 25/04/2007, p. 58)

Este título aparece na seção Brasil, de Veja, o que de demonstra a inserção deste enunciado num discurso sobre o país, sobre um fenômeno político da vida brasileira. Há aqui uma alteração proposta pelo enunciado. Observemos que o sentido de "muito família" se transforma em algo negativo e irônico, deslocado do seu sentido de qualidade de quem cuida e gosta de estar entre familiares. No caso, o que se quer é jogar com a expressão de modo a mostrar que a governadora "cuida de sua família" valendo-se do seu cargo. A implicitude é construída por um caminho de leitura proposto pelo locutor-jornalista, que fala da perspectiva de um enunciador crítico dos costumes nacionais, que extrai da expressão seu aspecto positivo, admitido no domínio privado, e ironizando o fato de a governadora ter determinado comportamento, considerado negativo na vida pública. Neste caso, o conteúdo implicitado é o de qualificação positiva da expressão "muito família", que é interditada nesta interpretação. Para compor o efeito de duplo sentido, porém, é necessário admitir a inserção do enunciado em outro campo de discurso: o de valorização da vida familiar. Assim, subentende-se que o destinatário faz uma interpretação para perceber a ironia proposta e também para vinculá-la a um sentido que não se pode considerar como positivo. $O$ enunciador-jornalista, portanto, assume o lugar de crítica ao comportamento da governadora. O efeito-leitor produzido é de um destinatário que compactua com esta crítica, concordando com a orientação argumentativa proposta. $\mathrm{O}$ acontecimento vem assim significar como algo negativo o fato de a governadora tratar questões públicas como se fossem particulares a partir de uma expressão que designa um comportamento positivo.

\section{(4) Negócios \& Carreira}

Inovação

Deu branco!

Como a parceria entre universidade e empresa privada gerou uma tinta branca de padrão mundial. (Época, 8/1/2007, p.49)

Este enunciado aparece na seção "Negócios\&Carreira" e apresenta o chapéu "Inovação". O olho explica o título de modo a oferecer ao destinatário a compreensão de uma interpretação proposta: como a parceria entre universidade e empresa privada gerou uma tinta 
branca de padrão mundial. Na interpretação proposta, tem-se o branco referindo-se ao resultado da pesquisa, que origina a tinta de cor branca. Este enunciado, recortado no interdiscurso, é trazido também em outra significação, que deve ser interpretado pelo destinatário. O resultado é visto como algo positivo - de padrão mundial. No entanto, o locutor-jornalista joga com outro sentido deste mesmo enunciado a partir de um recorte na memória deste dizer, aplicado a outros contextos, de ordem genérica, já que a expressão “deu branco!" refere-se a esquecimento. E é da perspectiva do enunciador genérico que o locutor-jornalista particulariza o significado e o constrói em sua literalidade, ou seja, o resultado de fato é branco. A direção interpretativa propõe, portanto, o sentido único do resultado branco. No entanto, há a memória do outro dizer que não deixa de significar, porém, não explicitamente. Ao jogar com a compreensão do destinatário, o locutor produz outro sentido e o integra ao dizer. Notemos que a responsabilidade pela interpretação fica a cargo do alocutário, imaginado como alguém que compartilha o mesmo universo cultural e capaz de interpretar o outro dizer e o deslocamento da expressão popular para o sentido literal. Dessa forma, é pela compreensão desta polifonia, que mostra a posição do locutor-jornalista oscilando entre posições enunciativas de conhecimento do duplo sentido e seu deslocamento para o sentido único, que podemos conhecer o mecanismo de produção do outro sentido proposto, subentendido e que se torna responsabilidade do enunciador. Há assim uma história de sentido deste enunciado que vem a compor o significado, mas não é levado em conta na direção interpretativa proposta. No entanto, o destinatário deve perceber esta história de sentido e a alteração realizada, no plano enunciativo, sob pena do efeito de sentido desejado pelo enunciador ficar comprometido.

\section{(5) Sociedade}

Escolas Inovadoras

Aqui os alunos são fora de série

Escola municipal paulista monta classes com alunos de idades diferentes e consegue alfabetizar mais. (Época, 8/01/ 2007, p. 82)

O enunciado "Aqui os alunos são fora de série" que corresponde ao título é inserido pelo locutor-jornalista na categoria sociedade, seção que define os assuntos determinados pela publicação como parte do que se pode considerar "sociedade". O chapéu "Escolas Inovadoras" define o assunto em questão, que permite a interpretação de que o tema é educação. O locutorjornalista joga com o duplo sentido da expressão "fora de série", que pode significar excepcional, algo que não é padrão. No entanto, a referência construída no enunciado é à série 
escolar, conforme se observa no olho - "Escola municipal monta classes com alunos de idade diferentes e consegue alfabetizar mais". Os alunos são, portanto, fora de série. O "aqui" do título é reescrito por "escola municipal" no olho. Ser fora de série, qualidade dos alunos, é implicitado, e o sentido proposto é o de alunos, que não tem série, ou não estão numa série, como categoria de reunião de estudantes para fins pedagógicos. Neste enunciado, novamente observamos o desdobramento feito pelo locutor-jornalista que imagina a partir de uma perspectiva de enunciador genérico, que supõe um leitor que pode compreender que este enunciado tem um duplo sentido: o fato de "o fora de série" poder ser uma qualidade dos alunos e não o lugar social que eles ocupam. O outro sentido, implícito, compõe o significado do enunciado, no qual não se assume esta duplicidade, silenciada pela orientação argumentativa estabelecida pela linguagem jornalística. Temos assim uma polifonia que deve ser recuperada pelo alocutário, que na perspectiva de destinatário, deve compreender a duplicidade proposta. Constroem-se assim duas posições de enunciação, uma delas relacionada à interpretação proposta e outra, que corresponde à margem do sentido, um sentido outro que deve ser interpretado para se realizar e que está implicitado.

Vida útil

Saúde

Dá para curar o mal pela raiz?

O Brasil começa a descobrir o valor de suas plantas medicinais. Eis as principais armas da fitoterapia. (Época, 16/10/2006, p.52).

Neste recorte, o assunto expresso no chapéu "Saúde" é categorizado como domínio da seção "Vida Útil". No título, o ditado "curar o mal pela raiz" integra a pergunta e é devolvido a um sentido literal. Desestabiliza-se assim o aspecto metafórico em favor de uma interpretação literal, proposta no enunciado pelo locutor-jornalista. Tal interpretação é explicada no olho "O Brasil começa a descobrir o valor de suas plantas medicinais. Eis as principais armas da fitoterapia”. O locutor-jornalista integra assim o sentido metafórico ao literal para compor o duplo sentido do enunciado, que deve ser interpretado pelo destinatário, no mesmo movimento empreendido pelo enunciador. No caminho de leitura proposto, o jogo entre os dois significados integra o mesmo discurso num favorecimento ao sentido literal proposto pela orientação dada à interpretação pelo chapéus e pelo olho. A perspectiva do enunciador genérico, portanto, faz o enunciado, orientado para um sentido literal, ter também o significado expresso no dito popular, 
que passa a integrar pela enunciação o enunciado. No entanto, observamos que há uma interdição para a interpretação do sentido figurado, que não corresponde ao que se quer dizer. Mas para a compreensão do enunciado e do jogo de sentidos, é necessário admitir os dois sentidos. Há, portanto, um já-la que significa, que está no interdiscurso e se integra ao enunciado, mas não é assumido. Dessa forma, o segundo sentido, tomado como conteúdo implicitado, pode ser considerado um subentendido a ser recuperado pelo destinatário. Observamos, porém, que o sentido figurado é mantido implicitado, de modo que o interlocutor perceba a operação de construção deste título, ressignificado em sua origem que se mantem na memória discursiva. Ocorre assim um deslocamento do domínio moral para o domínio científico para construir o significado proposto e a manutenção do discurso moral para garantia do duplo sentido.

\section{Conclusão}

A compreensão dos enunciados depende da apreensão de seus conteúdos implícitos, recursos linguísticos e comunicativos que estão à disposição do falante no jogo com a linguagem. Tomamos assim a implicitação como processo constitutivo da linguagem em uso, cujo sentido geral se define pelos intervalos entre o que se diz, o que não se diz, o que se silencia e o que se implicita. Deixar a entender também faz parte da interação verbal e a aceitação de pressupostos e subentendidos, como destaca Ducrot (1977 e 1987), é condição para a manutenção do diálogo, do processo comunicativo, sujeito a falhas, porém. Daí a necessidade de compreendê-los numa perspectiva que proponha uma análise não apenas formal, mas que inclua a dimensão subjetiva e histórica. Para tanto, é necessário um trabalho de interpretação em que se combinam informações do enunciado e dados do contexto. Como Ducrot, acreditamos ser necessário, observar o encadeamento no discurso para compreendê-los, o que torna a frágil distinção entre pressupostos e subentendidos e demonstra a impossibilidade de classificações a priori ou estabelecidas apenas no plano lingüístico.

Deste autor também compartilhamos a idéia de que há um quadro discursivo que se estabelece a partir dos conteúdos implícitos, em especial dos pressupostos. Daí a noção de que há uma orientação argumentativa, que impõe um modo de interpretação que silencia outras possibilidades. Este processo pode ocorrer implicitamente e é, conforme Guimarães, sustentado no já-dito.

No entanto, esta compreensão não pode descartar uma memória de sentidos que atravessa os sujeitos, ou seja, formulações que compõem a memória social e circulam em seus discursos. Nesse sentido, o trabalho do analista de linguagem é compreender como se produzem estes 
efeitos e os mecanismos de produção e interpretação desses enunciados. A compreensão do efeito de sentido, do ponto de vista analítico, depende ainda de uma apreensão do contexto, da subjetividade e da história que perpassa esses enunciados em suas condições de produção, para não ser apenas uma descrição. Só há sentido porque algo já fez sentido, isto é, o sentido é um efeito do já-dito constituído no interdiscurso e que tem a ilusão de unicidade. Isso signfica que a introdução de elementos para a análise - como o interdiscurso - vem a contribuir para uma compreensão mais ampla desses efeitos.

E porque a língua falha, não é transparente, temos a possibilidade de novos sentidos. Por essa razão, admitimos como nos alertam os príncípios da Análise do Discurso, que há deriva nestes enunciados, em oscilação permanente entre o que se diz, o que se pressupõe ou subentende-se, abrindo-se a possibilidade de novos sentidos e de intertextualidade. São, portanto, lugares de falha, e prova de que não há um sentido literal e um dizer único, tratados, portanto, como efeitos ilusórios no discurso. Há um confronto de sentidos que precisa ser compreendido a partir do que se implicita e da intertextualidade definida na rede de sentidos formada a partir do interdiscurso. Dessa forma, os múltiplos sentidos coexistem, numa relação com a alteridade constitutiva. Como nenhum dizer é completo, a falta é constitutiva e os conteúdos implícitos são espaços de significação necessários para a compreensão da linguagem em confronto com a alteridade. Daí admitirmos que os sentidos, mesmo aparentemente silenciados se manifestam na materialidade linguística no funcionamento mesmo dos conteúdos implícitos.

Ao tratarmos os títulos como elementos de significação na linguagem jornalística, consideramos que eles funcionam articulados a outros elementos paratextuais e ao próprio texto ao qual se vinculam, ou seja, não se pode compreendê-los isoladamente nem admitir que eles tem um funcionamento exclusivamente linguístico. Eles integram um acontecimento, cujo significado não pode ser depreendido na segmentalidade, mas sim em sua textualidade Decorre deste fato, a necessidade de incorporar na análise pressupostos da semântica histórica da enunciação.

\section{Referências}

A POLÍTICA do cachorro único. Veja, 6/12/2006, p. 75

AQUI os alunos são fora de série. Época, 8/1/2007, p. 82

DÀ para curar o mal pela raiz?. Época, 16/10/2006, p. 52

DEU branco!. Época, 8/1/2007, p.49 
DUCROT, O. Dizer e não dizer. Princípios de semântica lingüística. São Paulo: Cultrix, 1977.

O Dizer e o dito. Campinas: Pontes, 1987.

FONTCUBERTA, Mar de. La noticia: pistas para percibir el mundo. Barcelona: Paidós, 1993.

GOVERNADORA muito família. Veja, 25/4/2007, p.8

GUIMARÃES, E. Os limites do sentido : um estudo histórico e enunciativo da linguagem. Pontes: Campinas, 1995

Semântica do acontecimento: um estudo enunciativo da designação.

Campinas: Pontes, 2002b.

Texto e argumentação: um estudo de conjunções do português. Pontes:

Campinas, 2002a

LAGE, N. Linguagem jornalística. São Paulo: Ática, 1993.

MAINGUENEAU, D. Análise de textos de comunicação. São Paulo: Cortez Editora, 2002 O IMPÉRIO contra-ataca. Veja, 7/2/2007, p. 94

ORLANDI, E.P. \& GUIMARÃES, E. - "Unidade e dispersão: uma questão do texto e do sujeito. In: Série Cadernos PUC- 31. São Paulo: Educ, 1988. 